\title{
Distribuição longitudinal de sementes de milho com dosador de disco horizontal operando com uma ou duas saídas de sementes
}

\author{
Longitudinal distribution of maize seeds in the disk plate seed meter operating one or two seed \\ ejection points
}

\author{
Sandro Silva TeixeiraI Ângelo Vieira dos ReisII Antônio Lilles Tavares MachadoII \\ André Bisognin ${ }^{\text {III }}$ Hendrigo Alberto Torchelsen da Silveira ${ }^{\text {III }}$
}

RESUMO

O objetivo deste trabalho foi comparar os efeitos da utilização de dosador de sementes do tipo disco horizontal com orifícios circulares, operando com uma ou duas saídas de sementes sobre a precisão de distribuição longitudinal de sementes de milho. Para tanto, avaliou-se o dosador, em laboratório, com uma e duas saídas de sementes, em relação a 10 velocidades periféricas $\left(0,03\right.$ a $\left.0,30 \mathrm{~m} \mathrm{~s}^{-1}\right)$. O delineamento foi o inteiramente casualizado, com quatro repetições, totalizando 80 ensaios. O fator quantitativo referente à velocidade periférica do disco dosador foi estimado por meio de regressão polinomial de $2^{a}$ ordem. O comportamento do disco dosador operando com uma ou duas saídas foi semelhante, e a porcentagem de espaçamentos aceitáveis apresentou diferença significativa somente nas velocidades periféricas de 0,06 e $0,09 \mathrm{~m} \mathrm{~s}^{-1}$.

Palavras-chave: mecanização agrícola, semeadora de precisão, espaçamentos aceitáveis.

\section{ABSTRACT}

This study had the objective of comparing the effect of using the disk plate seed meter with circular holes operating with one or two seed ejection points in relation to the longitudinal precision of the maize seeds distribution. For the evaluation of this effect, the meter was tested in laboratory with one and two seed exits in ten peripheral disk plate speeds $(0.03$ to $\left.0.30 \mathrm{~m} \mathrm{~s}^{-1}\right)$. It was employed a complete randomized design with four replications, summing up 80 experimental plots. The peripheral speed quantitative factor was estimated through a $2^{\text {nd }}$ order polynomial regression. The behavior of the seed meter operating with one or two ejection points was similar, with significant difference only in peripherical speeds of 0.06 and $0.09 \mathrm{~m} \mathrm{~s}^{-1}$
Key words: agricultural mechanization, precision planters, percentage of singles.

\section{INTRODUÇÃO}

As semeadoras de precisão são máquinas agrícolas que enterram as sementes em sulcos, uma a uma ou em grupos, a distâncias regulares, segundo a densidade de semeadura pré-estabelecida (ABNT, 1996). O principal mecanismo dosador utilizado nas semeadoras de precisão é o do tipo disco horizontal com orifícios. Esse tipo corresponde a 77,3\% do total de mecanismos dosadores das semeadoras nacionais de tração mecânica (SILVA, 2003). Considerando somente as semeadoras de precisão utilizadas para a agricultura familiar, essa porcentagem aumenta consideravelmente, principalmente quando a tração animal é utilizada (TEIXEIRA, 2008). A principal concepção adotada pelos fabricantes de semeadoras de precisão de disco horizontal no Brasil utiliza um dosador de sementes para cada linha de semeadura; no entanto, em algumas aplicações específicas, como nas multissemeadoras, em que o espaçamento entre linhas é reduzido, é verificado o uso de um dosador de sementes para duas linhas.

Avaliando alguns fatores que afetam a distribuição longitudinal de sementes, foi constatado que o aumento da velocidade de deslocamento da

'Curso de Eletromecânica, Instituto Federal Sul Rio Grandense, Campus Pelotas, Praça Vinte de Setembro, 455, Centro, 96015360, Pelotas, RS, Brasil. E-mail: sandrot@cefetrs.tche.br. Autor para correspondência.

"Programa de Pós-graduação em Sistemas de Produção Agrícola Familiar, Departamento de Engenharia Rural, Universidade Federal de Pelotas (UFPel), Campus Universitário, Pelotas, RS, Brasil.

"IUFPel, Faculdade de Engenharia Agrícola, Campus Universitário, Pelotas, RS, Brasil. 
máquina (relacionado diretamente à velocidade periférica do disco dosador) diminui a porcentagem de espaçamentos aceitáveis (FURLANI et al., 1999; MAHL et al., 2004; GARCIA et al., 2006). Além desses fatores, MACHADO et al. (2005) consideraram que possam ocorrer falhas de deposição, profundidade e acondicionamento das sementes no solo.

Ainda em relação à velocidade periférica do disco, KEPNER et al. (1982) concluíram que a velocidade de 600 orifícios por minuto promoveria $100 \%$ de preenchimento desses orifícios por sementes de milho, em ensaio realizado com dosador do tipo disco horizontal. Os mesmos autores, no entanto, verificaram que o efeito da velocidade não atua isoladamente. Outros fatores, como a dimensão e a forma das sementes e do orifício do disco, também influenciam o percentual de enchimento. DELAFOSSE (1986) recomendou valores entre 0,29 e $0,315 \mathrm{~m} \mathrm{~s}^{-1}$ para velocidade periférica máxima do disco dosador.

O objetivo do presente trabalho foi avaliar a distribuição longitudinal de sementes de milho com um ou dois locais de ejeção de sementes, em relação a velocidades periféricas do disco dosador com orifícios circulares. Caso a regularidade da distribuição das sementes mantenha-se igual nessas duas condições, existe a possibilidade do projeto de uma semeadora com apenas um dosador para duas linhas de semeadura.

\section{MATERIAL E MÉTODOS}

O experimento foi realizado no Laboratório de Máquinas Agrícolas do DER (Departamento de Engenharia Rural) da Faculdade de Agronomia Eliseu Maciel (FAEM) da Universidade Federal de Pelotas (UFPel). Para a sua realização, foi utilizado um dosador de disco horizontal, disponível comercialmente, que possibilita o uso com uma ou duas saídas de sementes. A variação da velocidade periférica do disco dosador foi obtida por meio de bancada de testes de dosadores de sementes apresentada por REIS et al. (2007), a qual atende aos requisitos de avaliações laboratoriais de dosadores recomendados pela Associação Brasileira de Normas Técnicas (ABNT, 1994).

Foram utilizadas sementes de milho crioulas, sem nenhum tipo de tratamento. A escolha desse tipo de semente teve como objetivo testar a distribuição longitudinal de sementes com formas heterogêneas (achatadas e arredondadas), ou seja, sem a uniformidade das sementes selecionadas. As sementes foram classificadas por tamanho por meio de peneiras com furos de formato circular, com diâmetros de 9,0; 9,5 e $10 \mathrm{~mm}$, sendo utilizadas no experimento as sementes que ficaram retidas na peneira $9,5 \mathrm{~mm}$. As dimensões das sementes (comprimento largura e espessura) foram verificadas por meio de um paquímetro com resolução de $0,05 \mathrm{~mm}$. O número de sementes medidas foi o suficiente para que os coeficientes de variação e as médias das dimensões se estabilizassem. O disco dosador apresentava 50 orifícios circulares com diâmetro de $12 \mathrm{~mm}$ e espessura de $4 \mathrm{~mm}$, dispostos em duas carreiras.

O delineamento experimental foi do tipo inteiramente casualizado, com dois fatores experimentais: número de saídas dosador, com dois níveis (uma e duas) e velocidade periférica do disco dosador, com 10 níveis $(0,03 ; 0,06 ; 0,09 ; 0,12 ; 0,15 ; 0,18$; 0,$21 ; 0,24 ; 0,27$ e $0,30 \mathrm{~m} \mathrm{~s}^{-1}$ ), resultando em um fatorial 2x10, com quatro repetições para cada tratamento, totalizando 80 ensaios. Os níveis de velocidade foram escolhidos a partir da máxima velocidade periférica recomendada por DELAFOSSE (1986). Considerando um espaçamento entre linhas de $0,8 \mathrm{~m}$ e uma densidade de 50.000 plantas ha-1 ${ }^{-1}$ essas velocidades periféricas do disco dosador correspondem a velocidades de 1,9 a $19 \mathrm{~km} \mathrm{~h}^{-1}$ da semeadora no campo. O reservatório de sementes foi mantido nivelado com a metade da capacidade durante a condução dos ensaios. O número de sementes dosadas em cada ensaio foi de 250, conforme é recomendado pela ABNT (1994).

Para possibilitar a medição dos tempos entre as sementes, foi utilizado sistema eletrônico composto por unidade sensora fotoelétrica (constituída de placa com três fotodiodos TIL78 responsáveis pela emissão de feixe infravermelho e nove fototransistores TIL32 que recebem o feixe infravermelho) e unidade analógicadigital microprocessada (microcontrolador PIC16f876A, cinco circuitos integrados LM358, uma fonte de alimentação, filtros para evitar ruídos da rede e outros componentes discretos) conectada ao computador por meio de porta serial EIA-232. A passagem de uma semente pelo tubo condutor gera uma tensão de saída no receptor, que é comparada no circuito integrado LM358, onde há uma tensão de referência. Se a tensão vinda do receptor for maior, ele indicará ao microcontrolador que houve a passagem de uma semente. O sinal vindo do LM358 é interpretado pelo microcontrolador, que internamente faz o processamento desse sinal e envia-o ao computador. O processamento da contagem do número de sementes e do tempo relativo entre a passagem de sementes consecutivas ocorre por meio de um timer interno com precisão de $\pm 0,001$ s. O software RcomSerial v. 1.2 foi utilizado para aquisição e gravação dos dados em arquivo para posterior análise em planilha eletrônica. A unidade sensora apresenta erro de 1,2\% na contagem de sementes de milho para velocidades periféricas do 
disco dosador entre 0,03 e $0,30 \mathrm{~m} \mathrm{~s}^{-1}$. A unidade sensora de passagem das sementes foi adaptada na saída do dosador, no lugar do tubo condutor de sementes.

Para cada velocidade periférica do disco dosador, foi estabelecido um tempo de referência que corresponde ao tempo de passagem entre dois furos consecutivos. Esse tempo foi calculado com base no diâmetro médio, na velocidade periférica do disco dosador e no número de furos do disco, segundo a equação 1: $t_{r e f}=\pi \cdot \phi_{m} / n_{o} \cdot v_{p}$, em que: $t_{r e f}=$ tempo de referência (s); $\varnothing_{m}=$ diâmetro médio do disco dosador (m); $n_{o}=$ número de orifícios do disco dosador; $v_{p}=$ velocidade periférica do disco dosador $\left(\mathrm{m} \mathrm{s}^{-1}\right)$. Dessa forma, foram calculados os tempos de referências, que são diretamente proporcionais aos espaçamentos de referência para cada velocidade periférica do disco dosador. Estabeleceram-se, posteriormente, os tempos aceitáveis que representam os espaçamentos aceitáveis, de acordo com a ABNT (1994). Os tempos múltiplos e falhos também foram determinados pela equação 1 , considerando-se os múltiplos menores que $0,5 t_{\text {ref }}$ e os falhos maiores que $1,5 t_{\text {ref. }}$.

Como um dos fatores é qualitativo (saída) e tem somente dois níveis, para análise dos efeitos, foi realizada uma comparação pareada por meio do teste $\mathrm{F}$. No fator quantitativo (velocidade periférica), foi necessária a realização de uma regressão polinomial a fim de possibilitar a análise de seu efeito sobre a característica de resposta. A comparação de médias foi efetuada por meio do teste t. Em todos os testes estatísticos foi adotado o nível de significância de 5\%.

\section{RESULTADOS E DISCUSSÃO}

Os dados dimensionais das sementes (Tabela 1) indicam que o coeficiente de variação relativo à espessura foi maior que os do comprimento e da largura. Essa variação pode ser explicada pela utilização de peneiras com orifício circular para a classificação das sementes.

$\mathrm{Na}$ tabela 2, são apresentadas as porcentagens médias dos espaçamentos múltiplos,

Tabela 1 - Resultados dimensionais das amostras de milho crioulo utilizadas no experimento.

\begin{tabular}{lccc}
\hline Parâmetro & Comprimento & Largura & Espessura \\
\hline Média (mm) & 10,3 & 9,6 & 4,4 \\
$\begin{array}{l}\text { Desvio Padrão (mm) } \\
\text { Coeficiente de Variação }\end{array}$ & 0,7 & 0,4 & 0,6 \\
$\begin{array}{l}\text { \%) } \\
\text { Intervalo de Confiança- }\end{array}$ & 6,3 & 3,8 & 14,5 \\
$\alpha=0,95(\mathrm{~mm})$ & $\pm 0,5$ & $\pm 0,3$ & $\pm 0,5$ \\
\hline
\end{tabular}

aceitáveis e falhos. Observou-se que, conforme ocorre o acréscimo da velocidade periférica do disco dosador, a porcentagem média dos espaçamentos aceitáveis diminui, aumentando, consequentemente, as médias dos espaçamentos múltiplos e falhos. Esse efeito já era esperado, pois, quanto maior a velocidade, menor é o tempo disponível para a individualização das sementes pelos orifícios do disco dosador, resultando no aumento do número de espaçamentos falhos (orifícios vazios), o que está em consonância com os resultados descritos por FURLANI et al. (1999), SILVA(2000) e MAHL et al. (2004). Da mesma forma, o aumento da velocidade periférica provavelmente tenha dificultado a retirada das sementes extras dos orifícios pelo mecanismo exclusor, causando o aumento da porcentagem de espaçamentos múltiplos. A possibilidade de segregação de sementes, devido à forma e ao tamanho, ocasionada pelo movimento do dosador é pouco provável para a explicação do aumento dos espaçamentos múltiplos. JASPER et al. (2006), em testes de laboratório, concluíram que, após a passagem de 55.000 sementes de milho (arredondadas e achatadas) pelo tubo condutor, não houve esse tipo de segregação no interior do reservatório de sementes durante o processo de dosagem.

Também se observou que a porcentagem de espaçamentos múltiplos é superior à porcentagem de espaçamentos falhos em todas as velocidades analisadas, tanto para a condição de uma saída de semente, quanto para a de duas saídas. Isso poderia indicar excesso de folga entre o orifício e a semente, permitindo o alojamento de mais de uma semente no orifício, o que dificultaria a função do exclusor de sementes extras. No entanto, como a porcentagem de espaçamentos aceitáveis foi alta em todo o experimento, é mais provável que essa característica deva-se ao formato irregular das sementes crioulas, as quais foram apenas classificadas por tamanho. A forma irregular facilita o alojamento de mais de uma semente dentro do orifício do disco.

Os resultados da análise estatística indicaram que somente os efeitos simples do número de saídas e da velocidade periférica do disco dosador sobre a porcentagem de espaçamentos aceitáveis de milho foram significativos, não havendo interação entre número de saídas e velocidade periférica do disco.

O comportamento da regularidade de distribuição longitudinal de sementes, expressa pela porcentagem de espaçamentos aceitáveis, em função das variações na velocidade periférica do disco, foi explicado pelo ajuste de um polinômio de segunda ordem. O coeficiente de correlação entre os dados e a curva ajustada foi maior que 0,96 , tanto para uma, quanto para duas saídas de sementes (Figura 1). Os valores 
Tabela 2 - Porcentagem média de espaçamentos múltiplos, aceitáveis e falhos em relação à velocidade periférica do disco dosador na dosagem de sementes de milho, utilizando o dosador com uma saída e duas saídas.

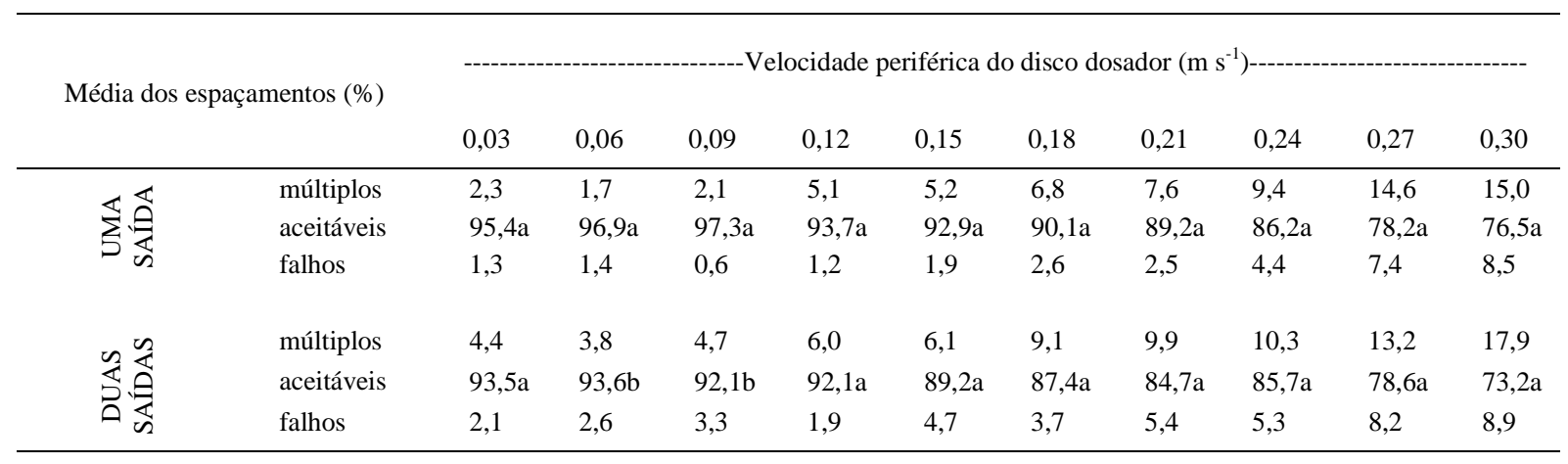

Médias não seguidas de mesma letra na coluna diferem pelo teste t, em nível de 5\% de significância.

foram decrescentes à medida que a velocidade periférica do disco aumentou devido às razões já apresentadas. De acordo com a figura 1, pode-se observar, pelo teste de comparação de médias, que somente as velocidades de 0,06 e $0,09 \mathrm{~m} \mathrm{~s}^{-1}$ diferiram significativamente em relação à porcentagem de espaçamentos aceitáveis com a utilização do dosador com uma ou duas saídas. Nessas velocidades, a porcentagem de espaçamentos aceitáveis foi significativamente maior para o dosador operando com apenas uma saída de sementes. Em princípio, não há justificativa para que somente nessas velocidades periféricas tenha havido diferença significativa entre o dosador operando com uma ou duas saídas de sementes. Nas velocidades periféricas maiores que $0,09 \mathrm{~m} \mathrm{~s}^{-1}$, em que a possibilidade de variação na distribuição longitudinal de sementes poderia ser maior, esse efeito não ocorreu. Possivelmente esses resultados discordantes estejam relacionados com o erro experimental. Observa-se que, embora tenha havido diferença significativa para o teste de médias (Figura 1), os valores de uniformidade de distribuição de sementes, nas velocidades periféricas de 0,06 e 0,09m $\mathrm{s}^{-1}$, para duas saídas, foram próximos aos de uma saída, indicando um baixo valor de dispersão dos resultados.

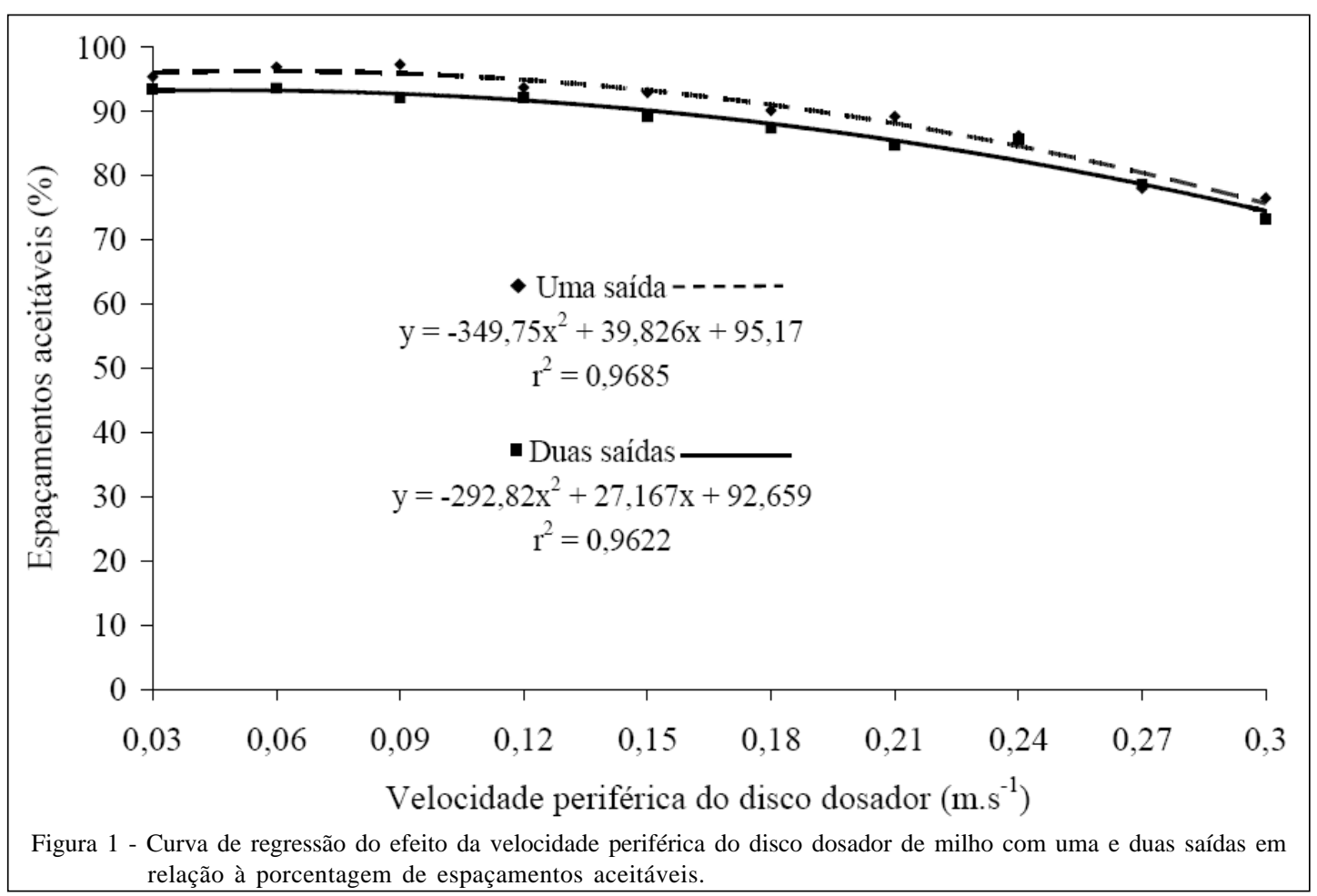

Ciência Rural, v.39, n.8, nov, 2009. 
A uniformidade de distribuição longitudinal de sementes, em todas as velocidades periféricas testadas com uma e duas saídas, encontra-se acima do mínimo recomendado para esse tipo de dosador, que é de 60\%, de acordo com COELHO (1996). Os resultados indicam, portanto, a possibilidade de utilização desse tipo de dosador para atender a duas linhas de semeadura de sementes de milho, já que a porcentagem de espaçamentos aceitáveis manteve-se acima de 73\% em todas as condições ensaiadas.

\section{CONCLUSÕES}

O dosador ensaiado, tanto com uma, quanto com duas saídas de sementes, apresentou regularidade de distribuição longitudinal, medida por meio dos espaçamentos aceitáveis, superior a 73\%, mesmo com a máxima velocidade periférica testada $\left(0,30 \mathrm{~m} \mathrm{~s}^{-1}\right)$, que corresponde a velocidade de deslocamento de $19 \mathrm{~km} \mathrm{~h}^{-1}$ de semeadura no campo. É possível, portanto, utilizar um único dosador do tipo disco horizontal com orifícios circulares para duas linhas de semeadura na dosagem de sementes de milho crioulo.

\section{REFERÊNCIAS}

ABNT. Associação Brasileira de Normas Técnicas. Projeto de Norma 04:015:06-004. Semeadora de precisão: ensaio de laboratório. São Paulo, 1994. 22p.

ABNT. Associação Brasileira de Normas Técnicas. Projeto de Norma 04:015:06-010. Semeadora e distribuidoras de fertilizantes e corretivos- terminologia: definições. São Paulo, 1996. 23p.

COELHO, J.L.D. Ensaio e certificação das máquinas para a semeadura. In: MIALHE, L.G. Máquinas agrícolas: ensaios e certificação. Piracicaba: Fundação de Estudos Agrários Luiz de Queiroz, 1996. p.551-570.

DELAFOSSE, R.M. Máquinas sembradoras de grano gruesso. Santiago: Oficina Regional de La FAO para America Latina y el Caribe, 1986. 48p.
FURLANI, C.E.A. et al. Características da cultura do milho (Zea mays L.) em função do tipo de preparo do solo e da velocidade de semeadura. Engenharia Agrícola, Jaboticabal, v.19, n.2, p.177-186, 1999.

GARCIA, L.C. et al. Influência da velocidade de deslocamento na semeadura do milho. Engenharia Agrícola, Jaboticabal, v.26, n.2, p.520-527, 2006.

JASPER, R. et al. Seleção de sementes de milho durante a simulação da semeadura com disco perfurado horizontal. Engenharia Agrícola, Jaboticabal, v.26, n.2, p.434-441, 2006. Disponível em: $<$ http://www.scielo.br/scielo.php?script=sci_arttext\&pid=S010069162006000200011\&lng=en\&nrm=iso> Acesso em: 8 mai. 2009. doi: 10.1590/S0100-69162006000200011

KEPNER, R.A. Et al. Principles of farm machinary. 3.ed. Westport: Avi, 1982. 527p.

MACHADO, A.L.T. et al. Máquinas para preparo do solo, semeadura, adubação e tratamentos culturais. Pelotas: UFPEL, 2005. 235p

MAHL, D. et al. Demanda energética e eficiência da distribuição de sementes de milho sob variação de velocidade e condição de solo. Engenharia Agrícola, Jaboticabal, v.24, n.1, p.150-157, 2004. Disponível em: <http://www.scielo.br/scielo.php?script=sci_ arttext\&pid=S0100-69162004000100017\&lng=en\&nrm=iso $>$. Acesso em: 8 mai. 2009. doi: 10.1590/S0100-69162004000100017

REIS, A.V. et al. Avaliação do desempenho de três mecanismos dosadores de sementes de arroz com vistas à semeadura de precisão. Revista Brasileira de Agrociência, v.13, p.393398, 2007.

SILVA, M.R. da. Classificação de semeadoras-adubadoras de precisão para o sistema plantio direto conforme o índice de adequação. 2003. 75f. Dissertação (Mestrado em Engenharia Agrícola) - Faculdade de Engenharia Agrícola, Universidade Estadual de Campinas. Faculdade de Ciências Agronômicas, Universidade Estadual Paulista, Botucatu, SP.

TEIXEIRA, S.S. Projeto conceitual de uma semeadora de milho e feijão voltada para a agricultura familiar de base ecológica. 2008. 113f. Dissertação (Mestrado em Ciências) - Universidade Federal de Pelotas, Pelotas, RS. 